\title{
TEN TRANSFORM EMERGENCY NOW! - FACING COVID 19 WITH OPEN AND FRUGAL INNOVATION
}

\author{
Dosi, Clio; \\ Cocchi, Nicolò; \\ Vignoli, Matteo \\ University of Bologna
}

\begin{abstract}
Against a pandemic, speed is crucial, and open innovation (OI) helps to empower the human capital distributed around the world to tackle the disease and to launch rapid testing of possible solutions. This article aims at showing an OI program - called "TEN" Transform Emergency Now! - ideated and developed by the University of Bologna to identify, design, and implement useful solutions to tackle specific issues coming from pandemics. With an action research-innovation management approach, the University developed two iterations to identify what elements to take into account to define a program that works for this effort. In TEN, Frugal Innovation (FI) principles were injected in a 10 days hackathon to favor the use of locally available resources and raw materials and exclude nonessential features. Results show that Frugality can become an element of OI by (1) pushing the team towards basic functionality and minimal features of the solutions and low-cost implementation. (2) Designing, in parallel with the solution, an 'implementation network', with a specific process design and program's organizational perspective. We believe that TEN has the potential to be an OI approach designed for emergencies.
\end{abstract}

Keywords: Open innovation, Design methods, Design practice

\author{
Contact: \\ Vignoli, Matteo \\ University of Bologna \\ Department of Management \\ Italy \\ m.vignoli@unibo.it
}

Cite this article: Dosi, C., Cocchi, N., Vignoli, M. (2021) 'TEN Transform Emergency Now! - Facing COVID 19 with Open and Frugal Innovation', in Proceedings of the International Conference on Engineering Design (ICED21), Gothenburg, Sweden, 16-20 August 2021. DOI:10.1017/pds.2021.558 


\section{INTRODUCTION}

Against a pandemic, speed is crucial, and open innovation (Chesbrough, 2003; Chesbrough, 2019) (OI) helps to empower the human capital distributed around the world to tackle the disease and to launch rapid testing of possible solutions (Chesbrough, 2020). Over the years, we have witnessed how "companies have used Hackathons and other forms of OI to generate heaps of creative ideas that never reach the point of implementation" (Dahlander and Wallin, 2020). During the Covid-19 pandemic, something has changed, and even companies started to openly work together in order to tackle the disease (Chesbrough, 2020), "putting the ability to create value before the opportunity to make a buck" (Dahlander and Wallin, 2020), to get to a solution as soon as possible (Chesbrough, 2020). This article aims at showing an OI program called "TEN" Transform Emergency Now! - ideated and developed by the University of Bologna that, through the university network, aims at involving different stakeholders to identify, design, and implement valuable solutions to tackle specific issues coming from pandemics as soon as possible. In TEN, Frugal Innovation (FI) principles were injected in a ten-day hackathon to favor the use of locally available resources and raw materials and exclude non-essential features. The goal of TEN is to deliver as soon as possible the developed solution concepts to help people facing the consequences of the disease. The TEN experience suggests that the program worked, and we believe that it could be taken into consideration from other universities around the world as an OI program that pushes for rapid implementations during emergencies.

\section{THEORETICAL BACKGROUND}

\subsection{The role of Open Innovation}

Chesbrough and Bogers (2014) define OI as "a distributed innovation process that involves purposely managed knowledge flows across the organizational boundary". From the firm-centric perspective, the OI process addresses innovation as an open system, where "ideas can come from inside or outside the company and can go to market from inside or outside the company as well" (Chesbrough, 2003). Most of the academic research on OI published in the last decade adopted this point of view, analyzing OI at a firm level (Bogers et al., 2017; Moretti, 2018). With a broader perspective, OI is described as a shift from the traditional closed innovation paradigm towards open models of collaboration (Gassmann and Enkel, 2004; Chesbrough, Vanhaverbeke, and West, 2006; Enkel, Gassmann, and Chesbrough, 2009). Collaborating with an open model means engaging with the company's innovation ecosystem, including startups, VC, research centers, inventors, and Universities. In the last few years, several OI programs between universities and industries were created. For instance, SUGAR $^{1}$ is a global network established in 2008 that brings together students, universities, and companies to innovate through a learning experience. Leading universities from all over the world, which are part of the network, enable students to form multidisciplinary teams and work together - for almost a year and under the supervision of an innovation coach - on design challenges provided by corporate partners. These OI initiatives present common characteristics such as a multidisciplinary collaboration (Enkel, Gassmann, and Chesbrough, 2009; Perkmann et al., 2013) between one (or more) university and one (or more) industry partner to engage students and researchers in business-driven activities (Chesbrough, Vanhaverbeke, and West, 2006). In this sense, OI does emerge as a collaborative research framework (Enkel, Gassmann, and Chesbrough, 2009; Perkmann et al., 2013). Moreover, OI may be leveraged to address complex social challenges (Chesbrough, Vanhaverbeke, and West, 2006; Enkel, Gassmann, and Chesbrough, 2009). During the pandemic, many Universities were involved in OI initiatives. For example, with \#EuvsVirus ${ }^{2}$, the European Commission involved 138 Universities across Europe and created 2,164 multidisciplinary and multinational teams, which sparked the development of 2,235 new cross-European partnerships by matching the best 120 teams with 500+ supportive partners from the public and private sectors. The program structure is defined as a Hackathon + Matchathon + EIC (European Innovation Council) COVID Platform and developed in two stages (April and May).

\footnotetext{
${ }^{1}$ https://sugar-network.org/

${ }^{2}$ https://www.euvsvirus.org/
} 


\subsection{The role of Frugal Innovation}

In times of crisis, scarcity is a key driver for innovation. Hossain et al. (2016) define a FI solution "as a resource-scarce solution (i.e., product, service, process, or business model) that is designed and implemented despite financial, technological, material or other resource constraints, whereby the final outcome is significantly cheaper than competitive offerings (if available) and is good enough to meet the basic needs of customers who would otherwise remain un(der)served'. FI emphasizes how innovations can be created for resource-constrained environments: it is based on what users need (and not 'what would be nice to have') and developed with a basic-functionality approach (and not 'Desirability and design'). FI was initially framed as a construct that explains how innovation happens in developing countries, developed by and for 'bottom of the pyramid' members, with a bottom-up approach (Basu et al., 2013). Besides resource constraints, FI usually happens in institutional voids, considering both a challenge and opportunity (Bhatti, 2012). In the middle of a severe pandemic, FI is an appropriate standard to develop a good-enough product that could answer the needs that emerge from this new pandemic scenario. The pandemic condition represents a "resource-constrained environment" since it provides new challenges without providing additional or new resources (Baker and Nelson, 2005). Moreover, given the fast and unexpected velocity in which things happen, institutions are often incapable of a prompt reaction, reflecting in an institutional void. In fact, in the most severe phase of Covid-19 in Italy, a small innovation company, Isinnova, was contacted by a local hospital to face the shortage of ventilation masks. They modified a commercially available snorkeling mask with a $3 \mathrm{~d}$ printed component to fix the shortage of hospital C-PAP masks for sub-intensive therapy ${ }^{3}$. Many other innovative solutions that were designed and implemented, bearing significant constraints, were happening worldwide (Harris et al., 2020). Literature on FI suggests what principles to follow in a pandemic if we need to design solutions in a situation of scarce-solutions and institutional void. First, FI "requires a deep understanding of the specific environment for which such products are developed" (Zeschky, Widenmayer, and Gassmann, 2011). For this reason, multinational companies that want to exploit FI for emerging markets usually establish local organizational structures in those emerging markets, facilitated by having on the R\&D team local people who bring personal experience related to the environment in which the product will be used. Second, the value architecture of FI focuses on minimality. The development team attitude is oriented toward a radical cost goal: low-cost manufacturing, materials, design, basic functionality, and minimal feature sets. In the middle of a severe pandemic such as Covid-19, the capability to deliver a solution as soon as possible is fundamental. OI can help speed up implementations (Chesbrough, 2020) by providing a framework to integrate knowledge and capabilities to different organizations. Leveraging the available knowledge with OI in these times of crises (Chesbrough, 2020) and the locally available resources for fast implementation, the University of Bologna designed and developed an OI program with FI principles that links universityindustry-government-public-environment through students' involvement. This program aims at rescheduling OI activities to maximize the chances of implementation.

\section{METHODOLOGY}

The study's objective is to understand how an OI program can be designed to ensure the delivery of fastly implementable solutions, as the ones requested in a pandemic time. We approached this question with an Action Research Innovation Management Framework (Guertler et al., 2020). As an action research framework, it embraces new and unexpected findings (called 'pivots') and their in-depth exploration, through iterations and research re-adjustments, by rigorously measuring research results. After the first design effort of the program TEN (a ten-day hackathon format), we developed two iterations of the program: OPER.TEN (4 challenges, 4 teams, dates: March 25th to April 5th) and UNA.TEN (4 challenges, 19 teams, dates: April 27th to May 8th). Our initial framing started with a focus on the hackathon literature. The hackathon format was chosen as it is one of the quicker OI methodologies used by universities and industries, which recently gained popularity among organizations to test their new products and generate new ideas (Rosell, Kumar, and Shepherd, 2014). The hackathon format (Mohajer Soltani et al., 2014) is 'classically' conceived as a few days intensive effort. Our first pivotal moment happened when we realized that the classical hackathon approach, expressed

\footnotetext{
${ }^{3}$ https://www.isinnova.it/easy-covid19-eng/
} 
as an ideation-based experience, could not answer our needs. In fact, in a pandemic, implementation is at least as necessary as the ideation phase, and we needed to develop an OI program that could adapt the hackathon ideation-driven structure towards an implementation-driven structure. We interpreted this insight with a lens of human-centric design and designed the first iteration of TEN with a user-centric OI program. This first iteration of TEN happened as OPER.TEN, with a Regional effort. When we 'acted' OPER.TEN, we measured its implementability, and we considered this first iteration a success. We evaluated OPER.TEN solutions in terms of actual implementation or implementability. After OPER.TEN three of four solutions have been implemented (Digitali e Uguali ${ }^{4}$, Esci i nonni ${ }^{5}$, Kit-Insegna), which means an implementation rate of 75\%. During OPER.TEN iterations, we encountered a second pivotal element. Often, during milestones, design teams presented several concepts, and according to the whole audience, most of them had a good users' desirability. However, the 'implementation mantra' often drove the internal discussion. For example, during a presentation, one of the teaching team members asked: "The design team comes out with five concepts. In my opinion, four are awesome, but only one is feasible in limited times. Which concept do we have to carry out? I am not used to selecting the more feasible one". A lengthy discussion emerged. In its actual structure and process, we realized that the program was not supporting the design team to design for the fastest implementable solution, not for the most desirable concept, as it should. A different lens was needed to build an effective implementation-driven OI program. We thus designed the second TEN iteration (UNA.TEN) upon FI's concept, trying to integrate the concepts of OI and desirability with frugality. To do this, we adapted course structure, processes, and tools. We then measured the implementation ratio of UNA.TEN and gathered insights regarding what worked in the OI and FI integration. For each iteration, we collected data (see Table 1) to analyse the relevance of the developed solutions in terms of implementability and how different stakeholders perceived the program in its defining elements.

Table 1. Data collection

\begin{tabular}{|c|c|}
\hline $\begin{array}{l}\text { Iterations' phases for the } \\
\text { action research innovation } \\
\text { management framework }\end{array}$ & Data collected \\
\hline $\begin{array}{l}\text { During OPER.TEN } \\
\text { ( } 4 \text { challenges, } 4 \text { teams, } \\
\text { dates: March } 25 \text { th to April } \\
\text { 5th) }\end{array}$ & $\begin{array}{l}\text { We recorded virtual meetings of the teams during the milestones (8 } \\
\text { hours) } \\
\text { - } \quad \text { First and final milestones, with remote participation from one } \\
\text { author to gather feedback from the partners engaged } \\
\text { - One author took field notes for a total of } 4 \text { hours of presentation }\end{array}$ \\
\hline $\begin{array}{l}\text { After the completion of } \\
\text { OPER.TEN }\end{array}$ & $\begin{array}{l}\text { - } 2 \text { semi-structured interviews with } 2 \text { partners engaged } \\
\text { A meeting with the teaching team of the University of } \\
\text { Bologna } \\
\text { - A meeting with all the students that attended the program. } \\
\text { - Revision of the documentation developed during the program }\end{array}$ \\
\hline $\begin{array}{l}\text { During UNA.TEN } \\
\text { ( } 4 \text { challenges, } 19 \text { teams, } \\
\text { dates: April } 27 \text { th to May } 8 \text { th) }\end{array}$ & $\begin{array}{l}\text { Even in this case, we attended both the sessions of } \\
\text { presentations for a total of } 15 \text { hours of recorded material }\end{array}$ \\
\hline $\begin{array}{l}\text { After the completion of } \\
\text { UNA.TEN }\end{array}$ & $\begin{array}{l}\text { - A meeting with the European teaching team } \\
\text { - A survey submitted to the European teaching team to collect } \\
\text { information regarding the implementability relevance of } \\
\text { teams' solution concepts (closed and open questions) } \\
\text { - Revision of the documentation developed during the program }\end{array}$ \\
\hline
\end{tabular}

The program description with its two iterations is reported below.

\footnotetext{
${ }^{4}$ http://www.digitalieuguali.it/index.html

${ }^{5}$ https://www.instagram.com/esci.i.nonni/?hl=it
} 


\section{TEN}

"TEN" is an OI program that links university, industry, government, public, and the environment through multidisciplinary teams of students. The program wants to fastly develop implementable solutions, to address specific challenges related to the Covid-19 emergency. At the moment, two different TEN programs - called OPER.TEN (regional) and UNA.TEN (European) - were launched. Both programs rely on similar processes designed to maximize the chances of implementation but present sequential adjustments. The final designed format is a ten-day experience and a humancentered design thinking process that integrates OI and FI principles. Format's activities are suitable to push rapid solutions implementation. The process is structured as described in Figure 1.

$1 \quad$ Kick-off

- Understand the design context in terms of actors involved, products and services already on the market, and innovations and initiatives in the field of the challenge

- Identification of users' problems

Desk research, Actors map, Map of the existing company assets, Benchmark of existing solution User interviews, Online surveys

2

\section{Research and need definition}

- Identification of the most relevant need of the main stakeholders

- Identification of opportunity areas

Stakeholders interviews, Users and experts' interviews, Personas, User journey map, Stakeholder map

3 Challenge definition and design space exploration

- Definition of the challenge reframed

- In-depth research of the context
Collaborative sense-making, Desk research

How might we" questions, Brainstorming, Rapid

prototyping (e.g., sketches, digital interfaces,

mockups), User test with stakeholders

5

- Test of the ideas

Prototyping, User test, Impact and feasibility, assessment

6

- Definition of the concepts

- Test of the concepts

Milestone

- Present the concepts to the teaching team and available partners

- Select the quicker concept to implement

- Definition of an action plan
Presentation, Feedback analysis, Gantt, List of experts, skills, and resources needed

List of constraints for features to build, System map

- Further development of the selected concept

- Plan a system prototype test

8

Concept refinement and communication

- Definition of the user experience

- Definition of the communication strategy

- Test of the prototype

User journey, Technical blueprint, Communication

strategy tools

9 Implementation

- System definition (e.g., skills, resources, timing, materials)

- Definition of an implementation roadmap

Final presentation

- Presentation of the outcome

Handover to organizations

Figure 1. TEN process structure, 10 days' goals, and tools. 
After the end of the final presentation, to guarantee a real social impact, the design team has to work for some other days with the partner involved during the process. That extra effort is needed to pass the baton and help the implementing partner go through the roadmap steps and then bring the outcome to life. The performed programs are described in sections 4.1 (OPER.TEN) and 4.2 (UNA.TEN). The differences between the programs mainly refer to the type of design challenges related to specific phases of the pandemic, the network of actors involved, and the management of the whole process.

\subsection{OPER.TEN}

OPER.TEN aims at developing implementable solutions to address four specific challenges related to phase 1 of the Covid-19 emergency. Designed and performed by the University of Bologna, it involved three universities from the same Region (UniMoRe, UniBo, and UniFe) that selected multidisciplinary teams of students with previous experience in OI. A coach was assigned to each team to lead the innovation process and connect the students with the relevant professors, experts, and professionals in the Universities' extended network. Table 2 describes the actors involved in OPER.TEN.

Table 2. Actors involved in the OPER.TEN program

\begin{tabular}{|l|l|l|}
\hline \multicolumn{1}{|c|}{ Actor } & \multicolumn{1}{|c|}{ Network involved } & \multicolumn{1}{c|}{ Main responsibilities } \\
\hline Design teams & MSc students & Design activities (Figure 1) \\
\hline Teaching team & Design Thinking coaches & $\begin{array}{l}\text { Students' recruitment, Identification } \\
\text { of possible partners, Methodological } \\
\text { support, Process and output } \\
\text { guidelines }\end{array}$ \\
\hline $\begin{array}{l}\text { Referent } \\
\text { professor }\end{array}$ & $\begin{array}{l}\text { An experienced academic in the field } \\
\text { of Innovation Management }\end{array}$ & Coordination of the program \\
\hline Support circle & $\begin{array}{l}\text { Professors, Companies, Municipality, } \\
\text { Start-up }\end{array}$ & Feedback during presentations \\
\hline
\end{tabular}

The 4 challenges provided to the teams were related to well-defined problems that occurred during "Phase 1 " of the Covid-19. Preliminary research was carried out to identify the most relevant challenges in the area, with 20 semi-structured interviews. Out of 30 ranked challenges, the organizing committee selected 4 in terms of closeness to university students' experience. We report 2 challenges as examples: (1) How might we support senior citizens who live alone and are currently experiencing isolation due to the lockdown, being more connected to other people, and doing physical activities without leaving their houses? (2) How might we minimize the risk of infections within supermarkets and grocery stores?.

\subsection{UNA.TEN}

UNA.TEN addresses real challenges related to the Covid-19 post-emergency phase 2 (post-lockdown). UNA.TEN is the first iteration of the program OPER.TEN. Based on the collected feedback provided by the network involved in that program, OPER.TEN was iterated by the Bologna teaching team and scaled within a European dimension. UNA.TEN was promoted by UNA Europa ${ }^{6}$, involving students from 7 partner universities. The main actors involved throughout the program are described in Table 3.

Table 3. Actors involved in the UNA.TEN program

\begin{tabular}{|c|l|l|}
\hline Actor & \multicolumn{1}{|c|}{ Network involved } & \multicolumn{1}{c|}{ Main responsibilities } \\
\hline $\begin{array}{l}\text { Design } \\
\text { team }\end{array}$ & $\begin{array}{l}\text { MSc students of the Una } \\
\text { Europa network from } \\
\text { different background }\end{array}$ & Design activities (Figure 1) \\
\hline Coach & $\begin{array}{l}\text { Professional with } \\
\text { consolidated experience in } \\
\text { innovation projects and the } \\
\text { design thinking approach. }\end{array}$ & $\begin{array}{l}\text { 1. Advising the design team about the tools and } \\
\text { activities in order to meet the daily goals. } \\
\text { 2. Finding experts to be interviewed and partners to } \\
\text { involve } \\
\text { 3. Finding companies or organizations interested in } \\
\text { further developing the concept. }\end{array}$ \\
\hline
\end{tabular}

${ }^{6}$ https://www.una-europa.eu/partners/ 


\begin{tabular}{|c|c|c|}
\hline $\begin{array}{l}\text { Teaching } \\
\text { team }\end{array}$ & $\begin{array}{l}\text { It is made up of all the } \\
\text { coaches involved in } \\
\text { UNA.TEN. }\end{array}$ & $\begin{array}{l}\text { 1. Have an overview of the progress of all projects } \\
\text { 2. Agree on the next steps and eventually adjust the } \\
\text { process } \\
\text { 3. Share tips and contacts. }\end{array}$ \\
\hline $\begin{array}{l}\text { Program } \\
\text { coordinat } \\
\text { or }\end{array}$ & $\begin{array}{l}\text { It is a coach from the teaching } \\
\text { team in charge of the } \\
\text { organization of the program. }\end{array}$ & $\begin{array}{l}\text { It is suggested to identify a network program } \\
\text { coordinator and a local coordinator, among the } \\
\text { teaching team members of the partner universities, } \\
\text { whose primary responsibilities are: } \\
\text { 1. The creation (or refinement) of the design process } \\
\text { 2. The organization of the network online meetings } \\
\text { (European teaching team update, kickoff, milestone } \\
\text { e final presentation) } \\
\text { 3. The recruitment of the design team members } \\
\text { 4. The organization of the coaching team update in } \\
\text { his/her university }\end{array}$ \\
\hline $\begin{array}{l}\text { Referent } \\
\text { professor }\end{array}$ & $\begin{array}{l}\text { A professor from one of the } \\
\text { Universities who represents } \\
\text { the academic side }\end{array}$ & $\begin{array}{l}\text { 1. Process definition } \\
\text { 2. Relationship with the academic partners } \\
\text { 3. Overall supervision on the program }\end{array}$ \\
\hline $\begin{array}{l}\text { Support } \\
\text { circle }\end{array}$ & $\begin{array}{l}\text { Professors, experts, corporate } \\
\text { professionals, start-up } \\
\text { connected to the University } \\
\text { networks }\end{array}$ & $\begin{array}{l}\text { They are involved only during the kick-off, } \\
\text { milestone, and final presentation in order to provide } \\
\text { the design teams with feedback and contacts }\end{array}$ \\
\hline Partners & $\begin{array}{l}\text { Firms or organizations that } \\
\text { may be interested in further } \\
\text { developing the concept or } \\
\text { cooperating in the final test of } \\
\text { the solution. }\end{array}$ & \\
\hline
\end{tabular}

To define the challenges, first, the University of Bologna teaching team performed desk research, interviewed stakeholders from public institutions (such as the Bologna municipality), and identified a set of 20 areas of intervention. The Una Europa Network then shared, discussed, and validated those areas and selected four of them. We report as an example two of the four final challenges: (1) How might we rethink entertainment and cultural activities during the Covid post-emergency period? (2) How might we protect our privacy and help fight dangers, fears, and misconceptions in a digital world? Each challenge was assigned to different local teams, as shown in Figure 2.
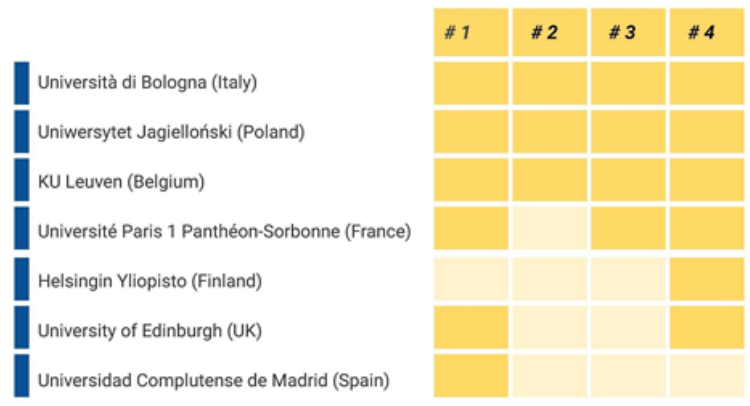

Figure 2. Challenges' distribution among the Universities (Source: UNA.TEN presentation)

UNA.TEN involved 100+ students, organized in 19 teams. Each local team worked separately on it, with a few joint meetings with other teams working on the same challenge to share insights and research material. To overcome social distances and remote working issues, the teaching team developed a Virtual Interaction Vademecum to foster coordination and cooperation among the local teams. Every local team managed the communications with the network through Slack, collected data through remote interviews and online surveys, shared all the gathered data in a digital workspace on Google Drive, and analyzed data collaboratively by using Miro, a visual collaborative platform. This structure aimed to address European problems in their local dimension, develop solutions tailored for the specific issue of the territory, connected to each university, still leveraging the potential of a European network where case studies and contacts of experts and professionals can be shared. 


\section{RESULTS}

\subsection{Now or Never: measuring the implementation effectiveness}

TEN aimed to identify a program that could quickly implement solutions to respond to Covid-19 issues rapidly. In the two iterations of the program, we measured the implementation success. The second iteration (UNA.TEN) involved 19 differently located challenges. We measured if the design teams' solution concepts were relevant in terms of implementability through the program's experts' survey. According to $90 \%$ of the experts, the solution concepts were likely to be highly impactful in implementation. We also asked to suggest what elements impacted the implementation effectiveness, and experts mentioned different elements. "Nowadays students start the implementation process with support from Centre for Technology Transfer CITTRU Jagiellonian University" (Uniwersytet Jagielloński, Poland, for the challenge related to Food \& Supply chain). "One partner is likely to implement it, others are interested. The Second solution is entirely based on existing technologies" (Uniwersytet Jagielloński, Poland, for the challenge related to Rethink culture). "The Edinburgh team had a stakeholder from the outset, and this helped them develop the solution through regular feedback and guidance" (Edinburgh University, UK, for the challenge related to culture). This gathered evidence allowed us to validate the program in terms of effectiveness, which is a valuable result for innovative interventions during a pandemic time of crises. Further investigations may also inquire about its efficiency.

\subsection{Designing for Frugality of the solutions}

This peculiarity often led the design team to focus on existing assets, rethinking their usability. To measure the frugality of solutions, we built on Bhatti et al. (2018) and classified the concept solutions developed considering the two FI dimensions: quality (measured by analyzing stakeholders' interest in implementation) and costs - by assigning 1 to 5 values at each dimension. The distribution around the matrix of the conceptual solutions developed is shown in Figure 3. Thirteen of twenty-three concept solutions fall within the FI quadrant (more than 50\%). To support the teams in designing for frugality, the process nudges design teams towards frugal solutions. In fact, the design process asks for a divergent effort of teams, and, in decisive moments, the team is asked to evaluate the different alternatives with an implementation lens. In particular, the team has to express how a possible solution coming out from the idea has the following characteristics: low costs, technology that is already available, the velocity of implementation. For instance, in the case of Digitali e Uguali, the design team addressed the initial challenge of remote activities by trying to help one-third of Italian families that did not own laptops, smartphones, and tablets and could not guarantee remote education to their children. The solution, a digital platform in which every person can donate new or unused digital devices, was launched by Yoox-Net-A-Porter just 33 days after the end of the project, and it provides free devices to needing families, enabling remote education (Mincolelli et al., 2020). This OPER.TEN result encouraged us to further push the program towards FI principles.

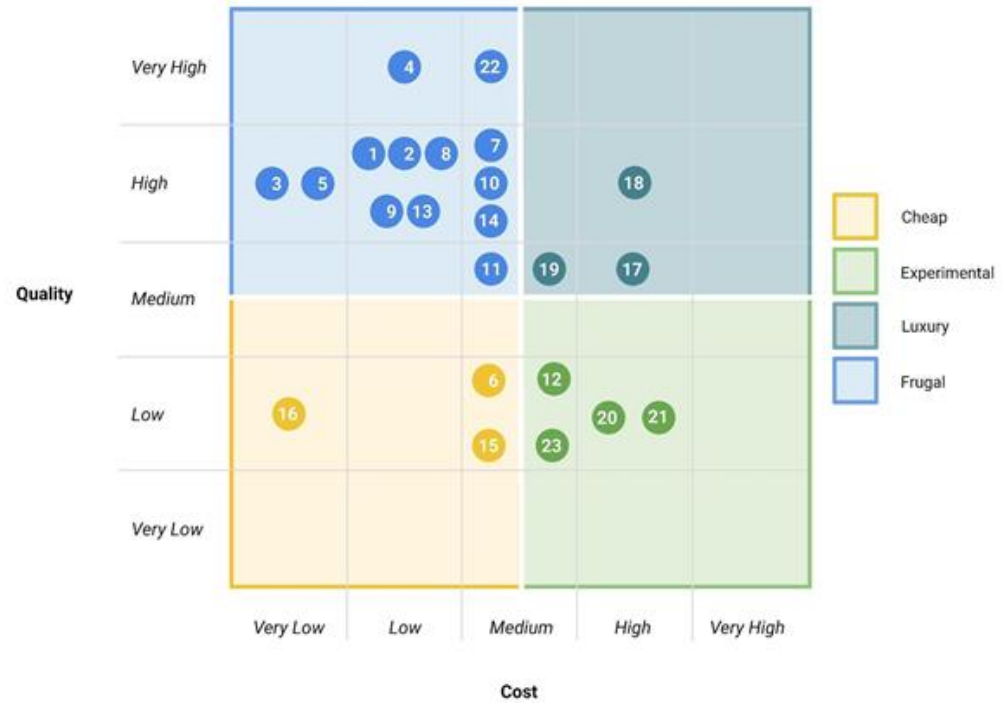

Figure 3. Distribution of the concept solutions (Adapted from Bhatti et al., 2018) 


\subsection{Designing the 'implementation network'}

TEN programs involve OI principles, not to leverage external ideas, but rather to build an 'implementation network', a network that assures the identification of champions that will take ownership in making the solution happen. The implementation network is built and identified while the solution is still in its definition phase. The program considers this as a design activity that is parallel to the solution definition activity. To do this, from an organizational point of view, TEN has specific attention in defining a support circle and partners (Table 2) since Champions are usually part of them. In terms of the design process, the responsibility of assessing and defining the 'implementation network' is split upon design teams and teaching teams, who continuously assess (during the ten days) whether the involved network presents possible champions. The design team, while defining solutions, need to: (1) continuously assess the presence of technological solutions that already exist on the market and respond to the identified solution concept; (2) identify a possible technological champion from the support circle or partners; (3) assess the presence of an implementation champion. At the same time, while defining the challenge, the teaching team assesses local actors interested in taking part in the challenge. In some instances, the Universities' press offices released local and national communications on the institutional channels to support interested organizations' identification. During solutions' definition, the teaching team's role is to ensure the building of an expanded network that could host an 'implementation champion' and push them to take ownership of the solution. Finally, during the last phases, both the design and the teaching team put an extra effort to pass the baton to the champions.

\section{DISCUSSIONS AND CONCLUSIONS}

The unexpected global pandemic caused by the Covid-19 virus pushed many organizations (e.g., private and public R\&D laboratories, Companies, and Universities) to fastly obtain results for promising innovative solutions, both medical and non-medical. In this context, the University of Bologna developed TEN, a program to develop solutions that could support people dealing with Covid-19, designed to minimize the solutions' time-to-market. With an action research-innovation management approach (Guertler et al., 2020), the University developed two iterations to inquire what elements define a program that works for such an effort. During the so-called "phase one" of the emergency, the first one with a regional program OPER.TEN, and the second during the "phase two" of the emergency, with the European program UNA.TEN. The result is a program that in 10 days builds on OI and FI principles and defines specific goals and tools that the design team should follow for a desirable and implementable solution. In particular, TEN, rather than focusing on ideation, pushes rapid implementations by (1) Pushing the team towards basic functionality and minimal features of the solutions and low-cost implementation. Solutions developed in TEN have been measured as frugal innovations; (2) Designing, in parallel with the solution, an implementation network', with a specific process design and program's organizational perspective. TEN was able to find the development capabilities in the context. FI elements that have been structurally embedded in the OI program increased the probability of the identified solutions to be fastly implemented. Implementability measures of the two iterations show that TEN reached the goal it was designed for, presenting a different way to involve users and stakeholders in a solution's design process. Concluding, even if this is a preliminary result based on two-iterations actions-research management innovation effort, we believe that other iterations around the TEN program could contribute to empower the definition of a program that could face the Covid-19 pandemic or other complex social challenges in emergencies and - more generally - to shed light on the role that FI may play in OI programs and their outcomes.

\section{ACKNOWLEDGMENTS}

We would like to express our gratitude to all the collaborative networks involved in both the programs. In particular, we express a big thanks to the coaching team, composed of Alice Colombo, Mario Di Nauta, Francesco D’Onghia, Silvia Marchini, Alberto Miti, Eleonora Musca, Michael Oggionni, and Elahe Rajabiani. 


\section{REFERENCES}

Baker, T. and Nelson, R.E. (2005), "Creating Something from Nothing: Resource Construction through Entrepreneurial Bricolage”, Administrative Science Quarterly, Vol. 50 No. 3, pp. 329-366.

Basu, R.R., Banerjee, P.M. and Sweeny, E.G. (2013), "Frugal innovation: core competencies to address global sustainability", Journal of Management for Global Sustainability, Vol. 1 No. 2, pp. 63-82.

Bhatti, Y., Basu, R.R., Barron, D. and Ventresca, M.J. (2018), Frugal Innovation: Models, Means, Methods, Cambridge University Press.

Bhatti, Y.A. (2012), What Is Frugal, What Is Innovation? Towards a Theory of Frugal Innovation, SSRN Scholarly Paper No. ID 2005910, Social Science Research Network, Rochester, NY, available at: https://papers.ssrn.com/abstract=2005910 (accessed 1 December 2020).

Bogers, M., Zobel, A.-K., Afuah, A., Almirall, E., Brunswicker, S., Dahlander, L., Frederiksen, L., et al. (2017), "The open innovation research landscape: established perspectives and emerging themes across different levels of analysis", Industry and Innovation, Vol. 24 No. 1, pp. 8-40.

Chesbrough, H. (2019), Open Innovation Results: Going Beyond the Hype and Getting Down to Business, Oxford University Press.

Chesbrough, H. (2020), "To recover faster from Covid-19, open up: Managerial implications from an open innovation perspective”, Industrial Marketing Management, Vol. 88, pp. 410-413.

Chesbrough, H. and Bogers, M. (2014), Explicating Open Innovation: Clarifying an Emerging Paradigm for Understanding Innovation, SSRN Scholarly Paper No. ID 2427233, Social Science Research Network, Rochester, NY, available at: https://papers.ssrn.com/abstract=2427233 (accessed 5 December 2020).

Chesbrough, H., Vanhaverbeke, W. and West, J. (2006), Open Innovation: Researching a New Paradigm, OUP Oxford.

Chesbrough, H.W. (2003), Open Innovation: The New Imperative for Creating and Profiting from Technology, Harvard Business Press.

Dahlander, L. and Wallin, M. (2020), "Why Now Is the Time for 'Open Innovation"”, Harvard Business Review, 5 June, available at: https://hbr.org/2020/06/why-now-is-the-time-for-open-innovation (accessed 5 December 2020).

Enkel, E., Gassmann, O. and Chesbrough, H. (2009), “Open R\&D and open innovation: exploring the phenomenon”, R\&D Management, Vol. 39 No. 4, pp. 311-316.

Flores, M., Al-Ashaab, A. and Magyar, A. (2009), “A Balanced Scorecard for Open Innovation: Measuring the Impact of Industry-University Collaboration”, in Camarinha-Matos, L.M., Paraskakis, I. and Afsarmanesh, H. (Eds.), Leveraging Knowledge for Innovation in Collaborative Networks, Springer, Berlin, Heidelberg, pp. 23-32.

Gassmann, O. and Enkel, E. (2004), "Towards a Theory of Open Innovation: Three Core Process Archetypes", presented at the R\&D Management Conference (RADMA) 2004, Lissabon, available at: https://www.alexandria.unisg.ch/274/ (accessed 5 December 2020).

Guertler, M.R., Kriz, A. and Sick, N. (2020), "Encouraging and enabling action research in innovation management", R\&D Management, Vol. 50 No. 3, pp. 380-395.

Harris, M., Bhatti, Y., Buckley, J. and Sharma, D. (2020), "Fast and frugal innovations in response to the COVID-19 pandemic", Nature Medicine, Vol. 26 No. 6, pp. 814-817.

Hossain, M., Simula, H. and Halme, M. (2016), "Can frugal go global? Diffusion patterns of frugal innovations", Technology in Society, Vol. 46, pp. 132-139.

Mincolelli, G., Cocchi, N., Dosi, C. and Vignoli, M. (2020), “'OPER.TEN’ Transform Emergency Now! - facing Covid-19 with Open Innovation and Human Centered Design”, Strategic Design Research Journal, Vol. 13 No. 3, pp. 658-668.

Mohajer Soltani, P., Pessi, K., Ahlin, K. and Wernered, I. (2014), "Hackathon - A Method for Digital Innovative Success: A Comparative Descriptive Study", presented at the 8th European Conference on IS Management and Evaluation - ECIME 2014 University of Ghent, Ghent, Belgium 11-12 September 2014, Academic Conferences and Publishing International Limited, pp. 367-373.

Moretti, F. (2018), “'Open’ Lab? Studying the Implementation of Open Innovation Practices in a University Laboratory”, International Journal of Innovation and Technology Management, Vol. 16 No. 01, p. 1950012.

Perkmann, M., Tartari, V., McKelvey, M., Autio, E., Broström, A., D’Este, P., Fini, R., et al. (2013), “Academic engagement and commercialisation: A review of the literature on university-industry relations", Research Policy, Vol. 42 No. 2, pp. 423-442.

Rosell, B., Kumar, S. and Shepherd, J. (2014), "Unleashing innovation through internal hackathons”, 2014 IEEE Innovations in Technology Conference, presented at the 2014 IEEE Innovations in Technology Conference, pp. 1-8.

Zeschky, M., Widenmayer, B. and Gassmann, O. (2011), "Frugal Innovation in Emerging Markets”, ResearchTechnology Management, Vol. 54 No. 4, pp. 38-45. 